\title{
The Whole Body Autoradiographic Studies on the Distribution of ${ }^{14} \mathrm{C}$-Labeled New 1,5-Benzothiazepine Derivative $\left({ }^{14} \mathrm{C}-\mathrm{CRD}-401\right)$ in Mice
}

\author{
Mari Sakuma, Masayoshi Yoshikawa and Yoshishige Sato \\ Biological Research Laboratory, Tanabe Seiyaku Co., Ltd.1)
}

(Received December 3, 1970)

\begin{abstract}
The distribution of a ${ }^{14} \mathrm{C}$-labeled coronary vasodilator, 3-acetoxy-2,3-dihydro-5-[2(dimethylamino)ethyl]-2-( $p$-methoxyphenyl)-1,5-benzothiazepin-4 $(5 \mathrm{H})$-one hydrochloride$\left({ }^{14} \mathrm{C}-\mathrm{CRD}-401\right)$, in mice was studied by means of whole body autoradiographic technique. Immediately after intravenous injection, ${ }^{14} \mathrm{C}-\mathrm{CRD}-401$ disappeared from the blood and accumulated in the heart muscle, lung, adrenal cortex, kidney, skeletal muscle and brain. The high radioactivity appeared rapidly in the stomach mucosa and bile, and consequently in the lumen of the stomach and intestine. Most organs which exhibited the highest radioactivity immediately after the injection showed gradually diminishing radioactivity during the first 24 hours. When administered orally to mice, ${ }^{14} \mathrm{C}-\mathrm{CRD}-401$ was rapidly and easily absorbed from the intestinal tract, and the radioactivity in various organs reached their maximal levels within 30 minutes. The experiments with pregnant mice administered ${ }^{14} \mathrm{C}-\mathrm{CRD}-401$ intravenously and orally demonstrated that there was a slow and slight penetration of radioactive materials to the fetuses through the placenta. Chromatographic investigation on the tissue-extracts of mice treated with ${ }^{14} \mathrm{C}-\mathrm{CRD}$ 401 demonstrated the compound was rapidly metabolized in mice after intravenous administration as well as after oral one.
\end{abstract}

The $d$-cis-isomer of 3-acetoxy-2,3-dihydro-5-[2-(dimethylamino)ethyl]-2-( $p$-methoxyphenyl) -1,5-benzothiazepin-4(5H)-one hydrochloride(CRD-401) was shown by Sato, et al. ${ }^{2}$ to be a potent coronary vasodilator. The metabolism of ${ }^{14} \mathrm{C}-\mathrm{CRD}-401$ in rat has been studied by Meshi, et al. ${ }^{3}$ ) who demonstrated this compound was metabolized by deacetylation, Ndemethylation and O-demethylation.

In the present paper, the distribution of ${ }^{14} \mathrm{C}-\mathrm{C} R \mathrm{R}-401$ in mice has been studied by a whole body autoradiographic technique. Determination of the unchanged compound and its metabolites in several organs was also carried out.

\section{Experimental}

Labeled Compound $-{ }^{14} \mathrm{C}-\mathrm{CRD}-401$ was synthesized in this laboratory. The compound carried ${ }^{14} \mathrm{C}$ label in ethyl side chain and its specific activity was $2.78 \mu \mathrm{Ci} / \mathrm{mg}$. The radiochemical purity was $98 \%$ as assayed by thin-layer chromatography.

Autoradiography _ Animals used were male ICR mice (body weight $20 \mathrm{~g}$ ) and pregnant mice two days before delivery (body weight 40 to $45 \mathrm{~g}$ ), from the J.C.L. Co., Ltd.

The compound was administered to mice either intravenously $(i . v$.$) or orally (p . o$.$) at the dose 2 \mathrm{mg} / \mathrm{kg}$ (i.v.) or $20 \mathrm{mg} / \mathrm{kg}$ (p.o.). Before oral administration, the mice were fasted for $5 \mathrm{hr}$, but water was given ad libitum. The stomach of some mice was ligated at the pylorus site before oral administration. At various times after administration, ranging from $30 \mathrm{sec}$ to $24 \mathrm{hr}$, the mice were anesthetized with ether and frozen by immersion in acetone cooled to about $-70^{\circ}$ with solid carbon dioxide. Sagittal sections, $40 \mu$ thick, of the mice were cut with Leitz-1300 cold microtome in a cryostat at $-15^{\circ}$. After being dried, the sections were brought into contact with Sakura X-ray films (non-screen type N). Exposure time was for 6 to 12 weeks. The photograph in the present paper was print of authoradiogram; the whiter the area on the photograph, the greater the concentration of radioactivity.

1) Location: Kawagishi, Toda-shi, Saitama.

2) M. Sato, T. Nagao, H. Nakajima and A. Kiyomoto, Arzneimitel-Forshing, accepted.

3) T. Meshi, J. Sugihara and Y. Sato, Chem. Pharm. Bull. (Tokyo), submitted. 
Radioactivity Measurements and Analytical Procedures-Male mice were sacrificed by decapitation at various times, ranging from $5 \mathrm{~min}$ to $24 \mathrm{hr}$, after either i.v. or p.o. administration. Several organs such as the liver, kidney, lung, spleen, heart, brain, testis, skeletal muscle and plasma were removed and each organ sample was homogenized with 5 volumes of cold $1 \% \mathrm{NH}_{4} \mathrm{OH}$. The radioactivity in the supernatant was determined by an Aloka Liquid Scintillation Spectrometer LSC-502.

Amounts of the unchanged compound in the liver, kidney, lung and brain were determined quantitatively as follows.

The homogenate was extracted with 4 volumes of benzene. Then the volume of benzene was reduced by evaporation and the remaining benzene from each sample was used for thin-layer chromatography. Nonlabeled CRD-401 was run as reference substance and detected by Drangendorff reagent. The radioactivity in the area with $R f$ value 0.64 was also assumed to be due to the unchanged compound by reverse dilution method.

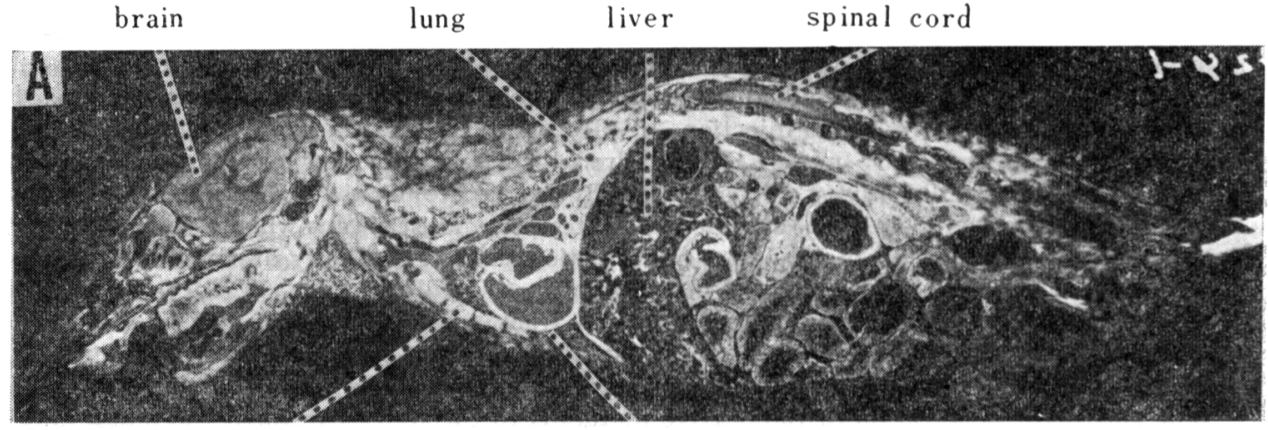

intercostal muscle

heart muscle
brain
blood vessels
adrenal gland
kidney

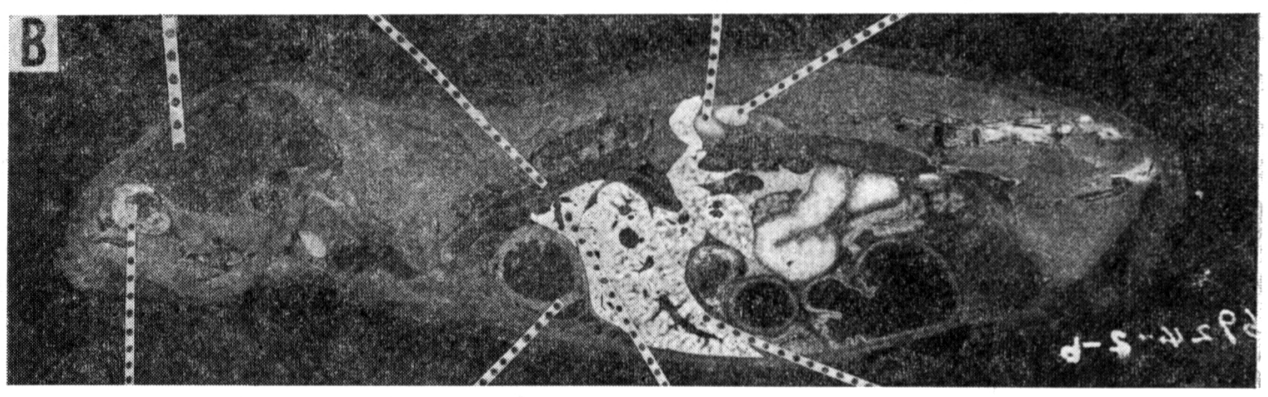

Herder's gland

heart muscle

lung

liver

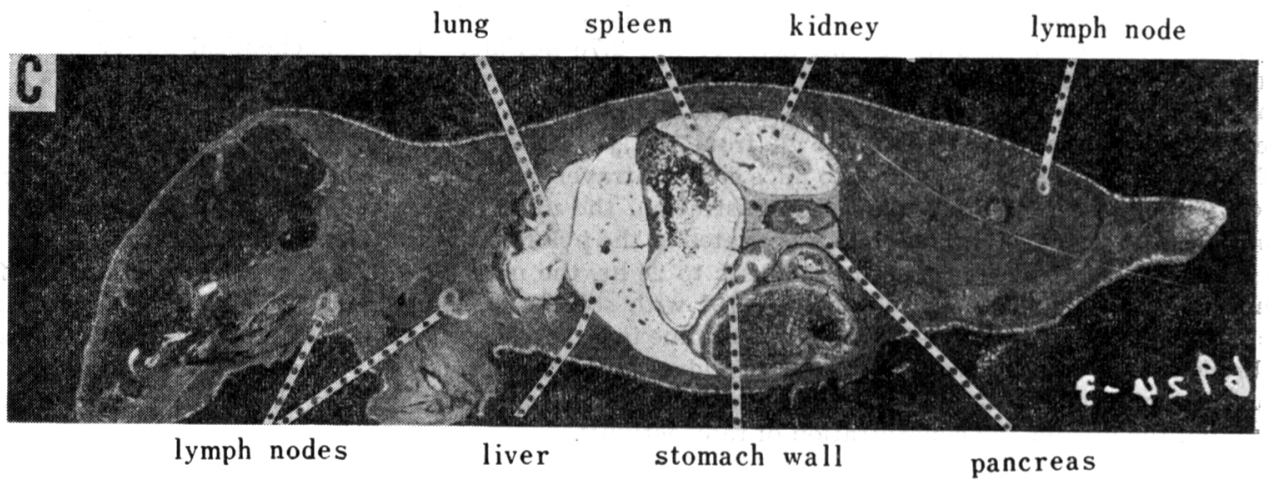

Fig. 1. Whole Body Autoradiograms Showing the Distribution of Radioactivity (White Areas) in Male Mice at Various Times after i.v. Injection of ${ }^{14} \mathrm{C}-\mathrm{CRD}-401$
A: $30 \mathrm{sec}$
B: 5 min
C: $30 \mathrm{~min}$ 


\section{Result}

\section{Autoradiography}

General Distribution-Fig. 1 showed autoradiograms obtained with male mice at 30 sec, 5 and $30 \mathrm{~min}$ after $i . v$. injection of ${ }^{14} \mathrm{C}-\mathrm{CRD}-401$. The compound left the blood very rapidly and accumulated in the lung, heart muscle, adrenal cortex, kidney and hypophysis at $30 \mathrm{sec}$ after the injection. The high concentration was also found in the stomach wall, pancreas, skeletal muscle, large blood vessel walls, thyroid and brain. The liver showed only a spotted pattern. Most organs which exhibited the highest radioactivity immediately after the injection showed gradually diminishing radioactivity during the first 30 min after the injection. Twenty four hr after the injection, the radioactivity was scarcely detected in the gall bladder, urinary bladder, intestinal contents and liver.

In pregnant mice, very small amount of radioactivity passed through the placental barrier (Fig. 2).

Fig. 3 showed autoradiograms obtained with male mice at $30 \mathrm{~min}, 1$ and $6 \mathrm{hr}$ after p.o. administration. ${ }^{14} \mathrm{C}-\mathrm{CRD}-401$ was rapidly and easily absorbed from the digestive tract and the radioactivity in each organ reached its maximum level within 15 to $30 \mathrm{~min}$ after the admi-

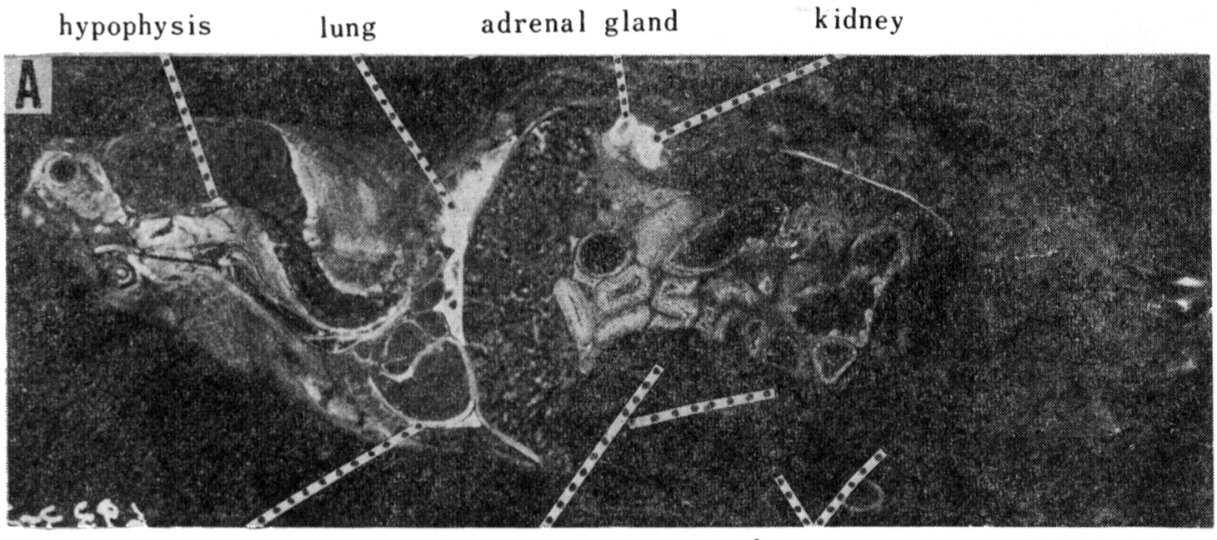

heart muscle

placenta

fetuses

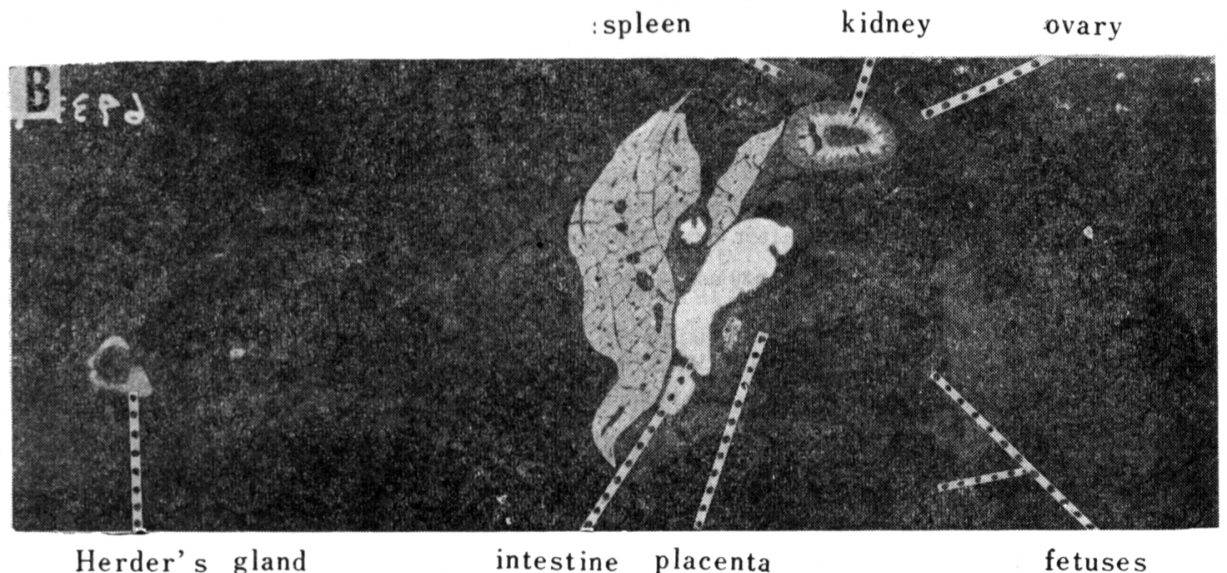

Fig. 2. Whole Body Autoradiograms Showing the Distribution of Radioactivity (White Areas) in Pregnant Mice after $i . v$. Injection of ${ }^{14} \mathrm{C}-\mathrm{CRD}-401$ 


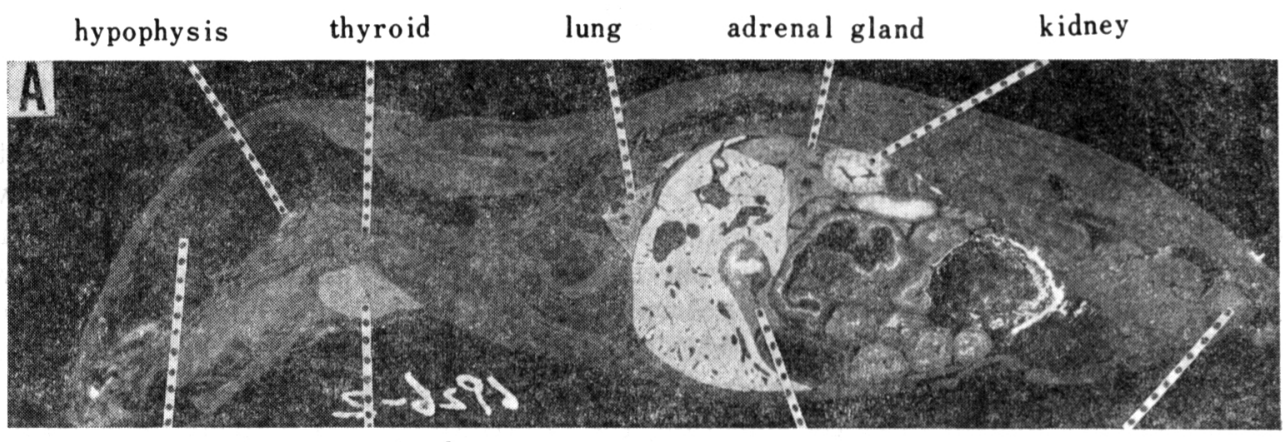

brain salivary gland

pancreas

Cowper's gland
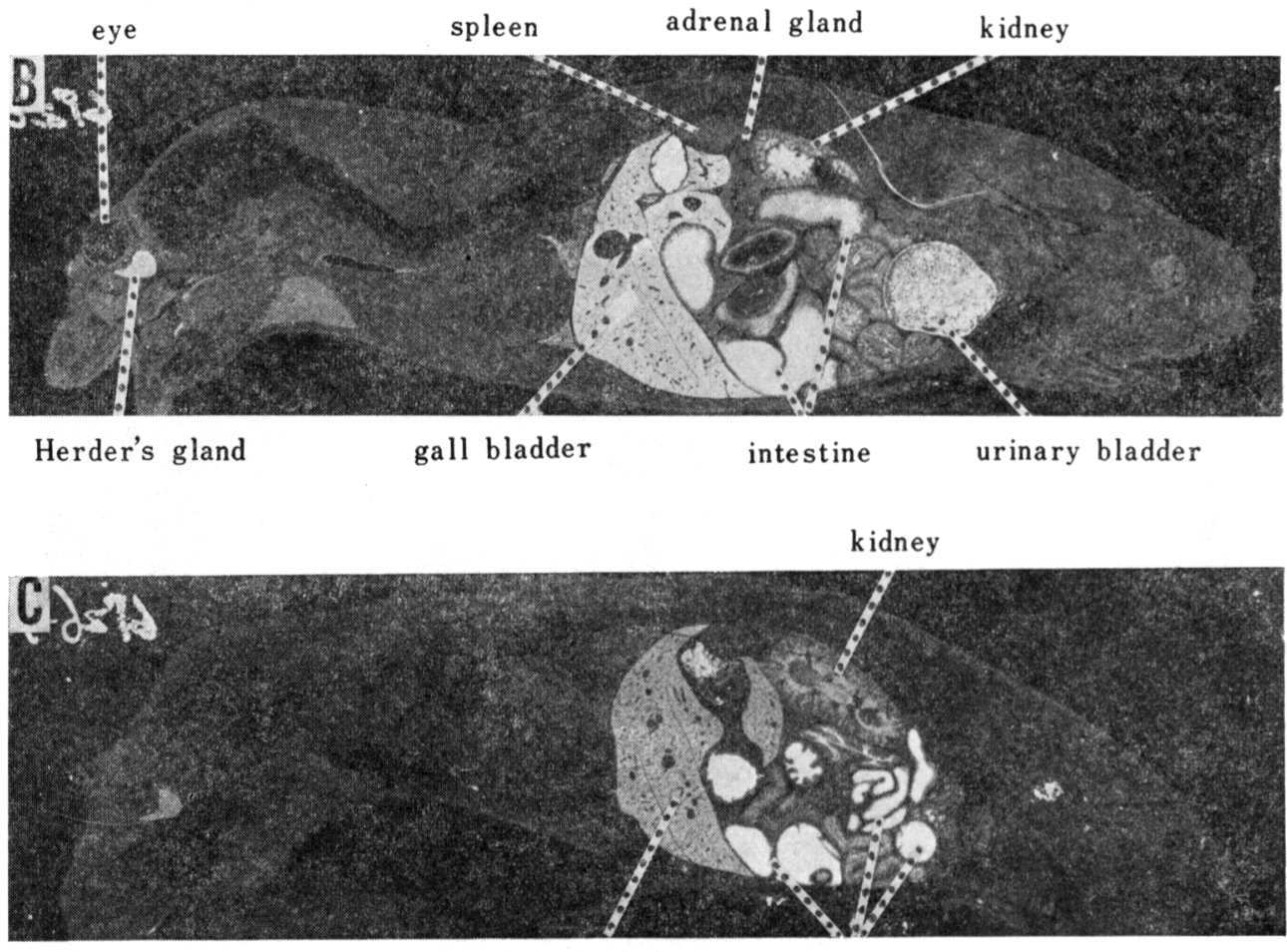

Herder's gland

liver

intestine

Fig. 3. Whole Body Autoradiograms Showing the Distribution of Radioactivity (White Areas) in Male Mice at Various Times after Oral Administration of ${ }^{14} \mathrm{C}-\mathrm{CRD}-401$

$$
\text { A: } 30 \mathrm{~min} \quad \text { B: } 1 \mathrm{hr} \quad \text { C: } 6 \mathrm{hr}
$$

nistration. The highest radioactivity was observed in the liver, kidney, salivary gland, Herder's gland, lung and hypophysis. Relatively high radioactivity was seen in the pancreas, spleen, heart muscle, thyroid and adrenal medulla. The concentration was very low in the blood and central nervous system. This distribution pattern did not changed at any of the time observed.

After p.o. administration of ${ }^{14} \mathrm{C}-\mathrm{CRD}-401$ to pregnant mice, the compound and/or its metabolites passed through the placental barrier more than after i.v. injection. However, the radioactivity in the fetal organs was extremely lower than that in corresponding maternal ones (Fig. 4). 


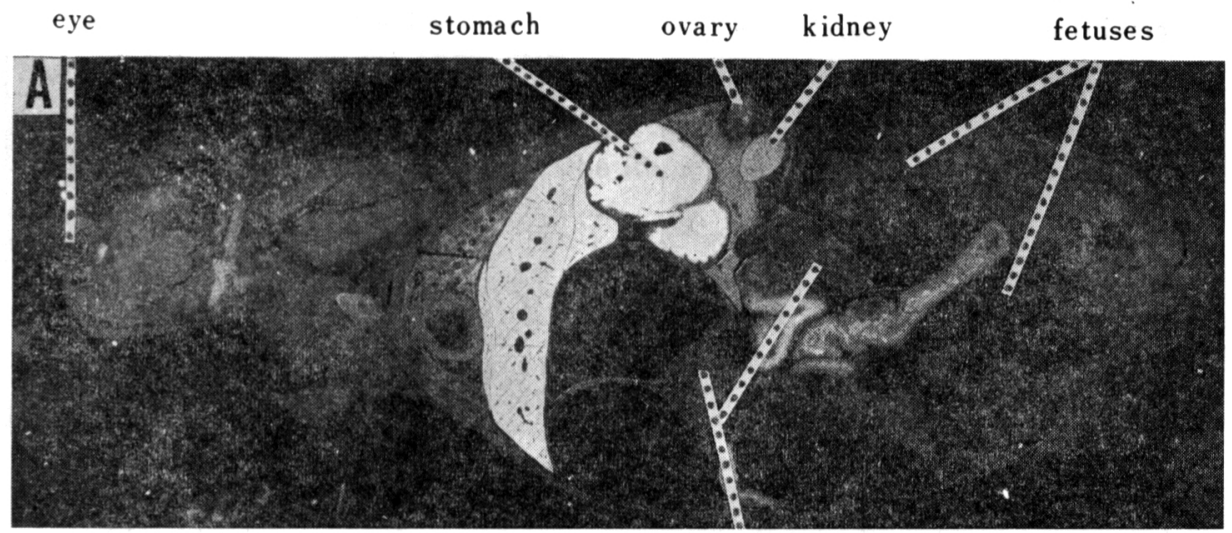

placenta

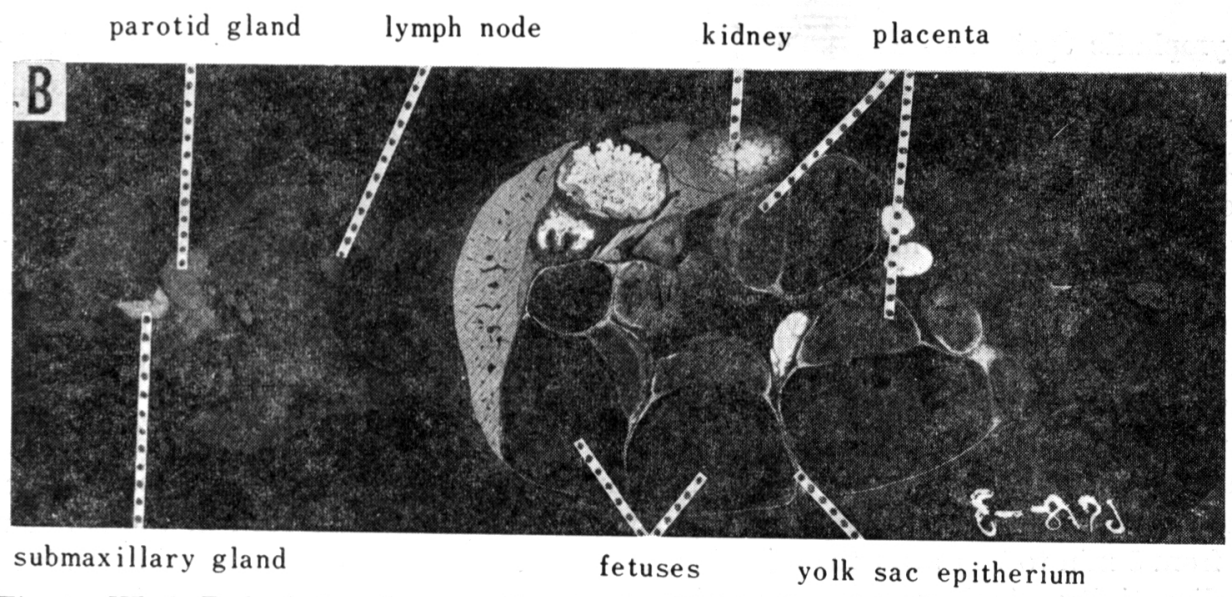

Fig. 4. Whole Body Autoradiograms Showing the Distribution of Radioactivity (White Areas) in Pregnant Mice after Oral Administration of ${ }^{14} \mathrm{C}-\mathrm{CRD}-401$

A: $30 \mathrm{~min} \quad \mathrm{~B}: 5 \mathrm{hr}$

A more detailed description on the distribution in various organs was as follows.

Central Nervous System — At $30 \mathrm{sec}$ after i.v. injection, a relatively high concentration of radioactivity was observed in the brain and spinal cord, where the radioactive maternals were rather uniformly distributed in the areas of grey matter (Fig. 5). This radioactivity, however, considerably decreased within $5 \mathrm{~min}$, and at the next observation time (30 min), the most of radioactivity has left the brain and spinal cord.

In the p.o. group, the radioactivity in the central nervous system was less than that in the blood throughout the observation period. The high concentration of radioactivity was found in the choroid plexus of the lateral and fourth ventricles, especially in the former, at various times after the administration.

Vascular System — The heart muscle showed the highest radioactivity at $30 \mathrm{sec}$ after i.v. injection. The radioactivity diminished greatly following $5 \mathrm{~min}$, but considerably high radioactivity still remained in the heart muscle up to $1 \mathrm{hr}$ after the injection.

In the p.o. group, the radioactivity was also highly concentrated in the heart muscle from $5 \mathrm{~min}$ to $1 \mathrm{hr}$ after the administration. The large blood vessel walls also contained about the same levels of radioactivity as the heart muscle. The concentration in the blood was lower than that in the most of the organs throughout the observation period. 


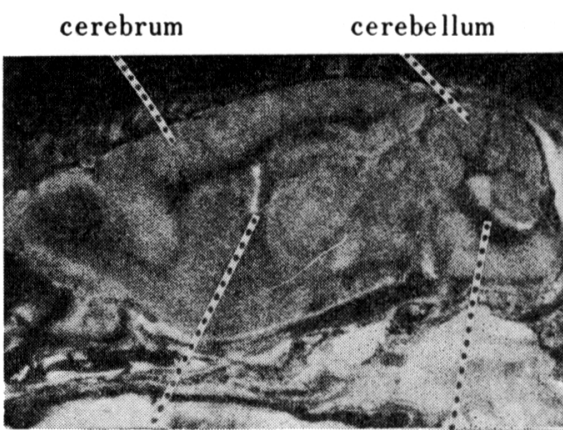

third ventricle

fourth ventricle

Fig. 5. Detail Autoradiogram of the Brain at $30 \mathrm{sec}$ after $i . v$. Injection of ${ }^{14} \mathrm{C}-\mathrm{CRD}$ 401

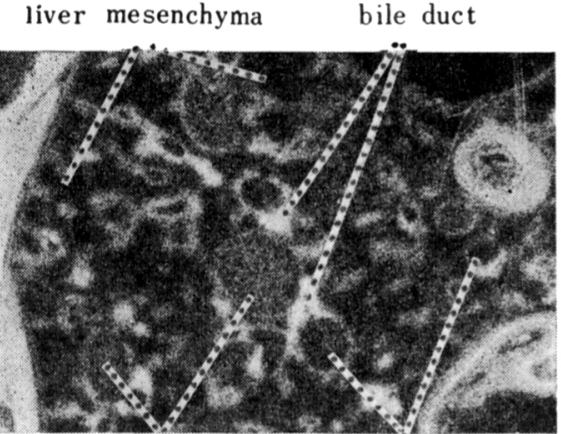

hepatic vein

Fig. 6. Detail Autoradiogram of the Liver at $30 \mathrm{sec}$ after $i . v$. Injection of ${ }^{14} \mathrm{C}-\mathrm{CRD}$ 401

Lymphatic System — - The spleen, lymph nodes and thymus showed a relatively high radioactivity from 5 to $30 \mathrm{~min}$ after the administration. The radioactivity was mainly concentrated in the white pulp of the spleen and in the cortex of the lymph nodes and thymus.

Digestive System — The liver showed a spotted pattern characteristic of other lipophilic compounds, at $30 \mathrm{sec}$ after the $i . v$. injection (Fig. 6) and then the radioactivity was progressively increased. From 5 min to $6 \mathrm{hr}$, the concentration in the liver remained extremely high, while at $24 \mathrm{hr}$ a little radioactivity was scarcely detectable. In the p.o. group, ${ }^{14} \mathrm{C}-\mathrm{CRD}-401$ and/or its metabolites were strongly and rapidly taken up by the liver, where the highest radioactivity was found already at $5 \mathrm{~min}$. The gall bladder and interlobular bile ducts showed the strong radioactivity throughout the observation period. In the pancreas, the high radioactivity was also detectable from $30 \mathrm{~min}$ to $1 \mathrm{hr}$ after the injection. The radioactive materials appeared to distribute uniformly in the endocrine and exocrine glands. The pancreatic ducts showed the intense radioactivity. A high radioactivity was also seen in the submaxillary gland from $5 \mathrm{~min}$ to $1 \mathrm{hr}$ after the injection, whereas the sublingual and parotid glands showed less radioactivity. Thirty sec after the $i . v$. injection, the stomach wall, especially the fundic

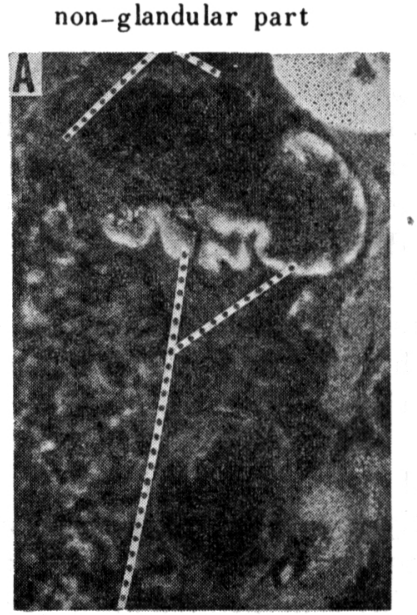

fundic glandular part

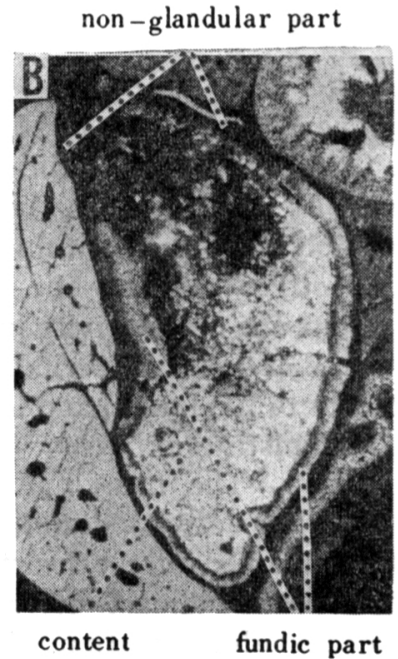

content fundic part

Fig. 7. Detail Autoradiograms of the Stomach at $30 \mathrm{sec}$ (A) and $30 \mathrm{~min}$ (B) after $i . v$. Injection of ${ }^{14} \mathrm{C}-\mathrm{CRD}-401$ 
glandular part showed the highest radioactivity (Fig. 7A). Five min and later, the contents of the stomach were strongly labeled, probably indicating an excretion of radioactive materials into the lumen, although regurgitation from the duodenum might also play a part (Fig. 7B). The mucosa of the caecum, colon and rectum were labeled more strongly than the serosa of them, however, no excretion into the lumen was demonstrated. The radioactivity in the lumen of the small intestine increased according to the lapse of the time. The source of this high radioactivity was probably due to the bile.

The experiments with p.o. administration demonstrated that the compound was rapidly and easily absorbed from the digestive tract. By pylorus ligation, the radioactivity levels in the various organs fell markedly, which suggested that the absorption of this compound took place in the intestinal tract (Fig. 8).

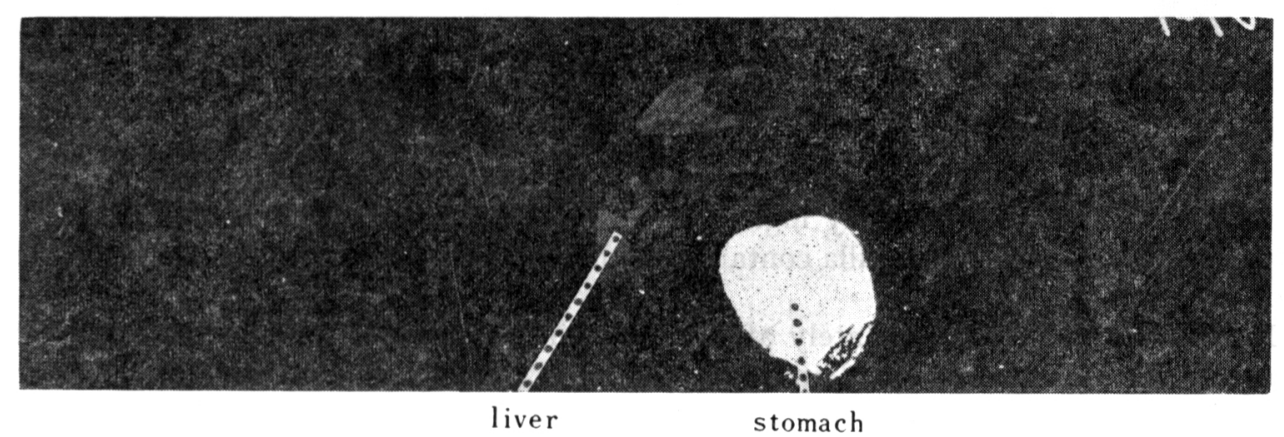

Fig. 8. Whole Body Autoradiogram Showing the Distribution of Radioactivity (White Areas) in Mouse Whose Stomach was Ligated at Pylorus before Oral Administration of ${ }^{14} \mathrm{C}-\mathrm{CRD}-401$

Respiratory System_ The highest radioactivity was observed in the lung. The readioactivity remained there for about $3 \mathrm{hr}$, and then diminished gradually. The mucous membrane of the nose showed a fair amount of radioactivity for about $1 \mathrm{hr}$.

Urogenital System_-The high and uniform distribution of radioactivity was initially observed in the kidney. Later, the radioactivity was localized adjacent to the border between the cortex and medulla (Fig. 9). The restrictively high concentration of radioactivity in this part remained for $6 \mathrm{hr}$ and more. The urinary bladder contained a large amounts of radioactivity throughout the observation period.

The relatively high and uniform distribution was observed in the ovary of pregnant mice. On the other hand, the uptake of radioactive materials in the testis and seminal vesicle of male mice was rather low but it was

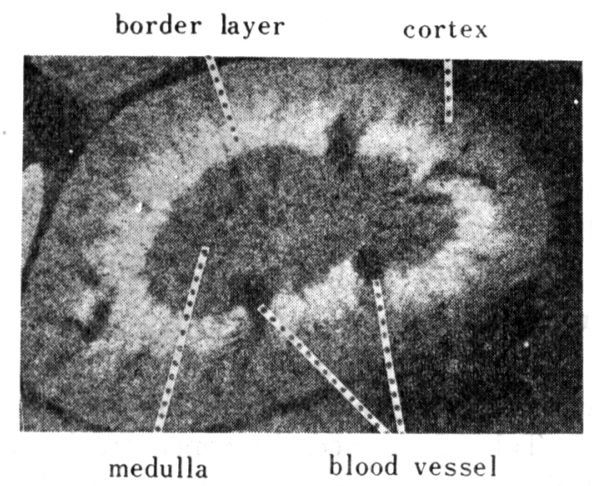

Fig. 9. Detail Autoradiogram of the Kidney at $1 \mathrm{hr}$ after $i . v$. Injection of ${ }^{14} \mathrm{C}-\mathrm{CRD}-401$ noted that a fair amount of radioactivity remained in some glandular organs such as Cowper's gland and Tyson's gland.

Endocrine Organ — The hypophysis exhibited the high radioactivity immediately after the administration and retained the higher level compared with that of the brain up to $6 \mathrm{hr}$. A relatively high was also found in the thyroid in the early period. The adrenal cortex exhibited the highest radioactivity immediately after the i.v. injection (Fig. 10A), however, the radioactivity in the cortex greatly diminished during the following $5 \mathrm{~min}$. Thereafter, the 


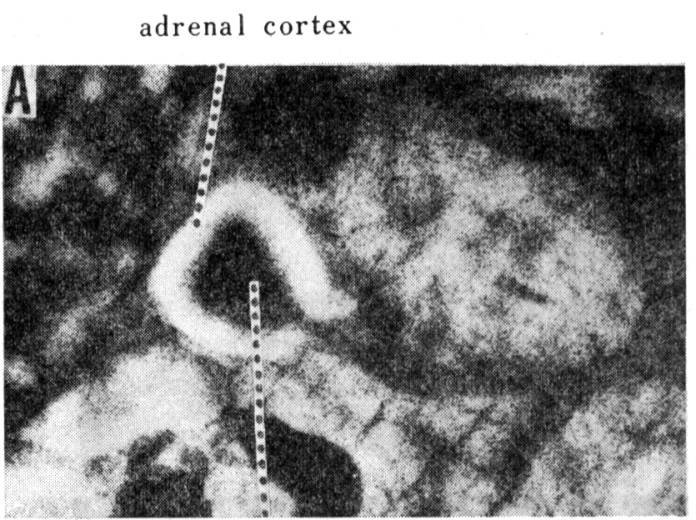

adrenal medulla adrenal cortex border layer

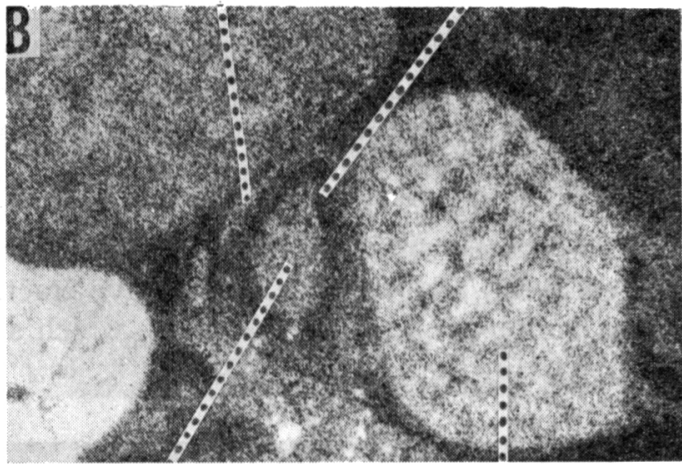

adrenal medulla kidney

Fig. 10. Detail Autoradiograms of the Adrenal Gland at $30 \mathrm{sec}(\mathrm{A})$ and $1 \mathrm{hr}(\mathrm{B})$ after i.v. Injection of ${ }^{14} \mathrm{C}-\mathrm{CRD}-401$

adrenal medulla showed relatively high radioactivity and retained it longer (Fig. 10B). In the p.o. group, the adrenal medulla contained higher radioactivity than the cortex throughout the observation period.

Muscle and Fat - Immediately after the $i . v$. injection, muscle, especially cervical and intercostal muscle, tongue and diaphragm exhibited the highest radioactivity. The radioactivity in these parts decreased slightly during the following $5 \mathrm{~min}$, and relatively high radioactivity remained up to $1 \mathrm{hr}$ after the injection. In the p.o. group, a moderate radioactivity was observed in the muscle from $15 \mathrm{~min}$ to $1 \mathrm{hr}$ after the administration. The concentration of radioactivity in the brown fat exceeded that in the muscle throughout the observation period.

Placenta and Fetuses - In the i.v. group, very small amount of radioactivity passed through the placental barrier. A little radioactivity was detectable in the fetal liver, and intestine at $30 \mathrm{~min}$ but the radioactivity decreased greatly at $2 \mathrm{hr}$. In the p.o. group, the compound and/or its metabolites passed more easily through the placental barrier than in the i.v. group. At $30 \mathrm{~min}$, some amount of radioactivity were observed in the fetal liver, intestine and lung. The radioactivity levels in the fetuses showed successively increasing during $2 \mathrm{hr}$, thereafter decreased slowly but progressively. The concentration of radioactivity in the fetal organs was extremely lower than that in the corresponding maternal ones at all observation period. Considerable amount of radioactivity was found in the part of the yolk sac, adjacent to the chorioallantoic membrane.

\section{Organ Radioassay}

In order to determine the concentration of radioactivity in organs, a quantitative evaluation was carried out on the several organs.

Table I showed the concentration of total ${ }^{14} \mathrm{C}$ in the several organs after i.v. or p.o. administration of ${ }^{14} \mathrm{C}-\mathrm{CRD}-401$. In the $i . v$. group, the highest levels of radioactivity were noted in various organs except the liver at $5 \mathrm{~min}$, and obviously decreased thereafter. In the p.o. group, the pattern of the distribution was almostly similar to that in the i.v. group. The only significant difference appeared in the liver where maximal concentration of radioactivity occured earlier than other organs.

Fig. 11, 12, 13 and 14 illustrated the time-course of unchanged compound and its metabolites in the liver, kidney, lung and brain, respectively, after the $i . v$. injection. The percentages of the unchanged compound were always lower than those of the radioactive metabolites in all organs examined. Particularly in the liver, the percentage of the unchanged compound was low as compared with that of metabolites even 5 min after the administration. 
TABLE I. Distribution of ${ }^{14} \mathrm{C}$ in Various Tissues of Mice after Intravenous $(2 \mathrm{mg} / \mathrm{kg})$ or Oral $(20 \mathrm{mg} / \mathrm{kg})$ Administration of ${ }^{14} \mathrm{C}-\mathrm{CRD}-401$

\begin{tabular}{|c|c|c|c|c|c|c|c|c|c|c|c|}
\hline & \multicolumn{11}{|c|}{ Dose percentage of ${ }^{14} \mathrm{C}$ per gram tissue or ml plasma $(\%)$} \\
\hline & \multicolumn{5}{|c|}{$i . v$. } & \multicolumn{6}{|c|}{ p.o. } \\
\hline & $5 \mathrm{~min}$ & $10 \mathrm{~min}$ & $1 \mathrm{hr}$ & $3 \mathrm{hr}$ & $24 \mathrm{hr}$ & $15 \mathrm{~min}$ & $30 \mathrm{~min}$ & $1 \mathrm{hr}$ & $3 \mathrm{hr}$ & $6 \mathrm{hr}$ & $24 \mathrm{hr}$ \\
\hline Liver & 10.20 & 13.70 & 13.40 & 6.71 & 3.34 & 16.50 & 10.50 & 10.34 & 6.30 & 5.02 & 1.87 \\
\hline Kidney & 10.10 & 6.98 & 3.59 & 2.52 & 0.97 & 6.56 & 6.68 & 4.32 & 3.38 & 3.09 & 0.60 \\
\hline Lung & 9.52 & 6.93 & 2.95 & 1.62 & 0.41 & 3.59 & 3.12 & 3.00 & 2.22 & 1.49 & 0.24 \\
\hline Spleen & 5.33 & 5.23 & 1.76 & 0.45 & 0.39 & 2.17 & 1.90 & 1.87 & 1.27 & 0.68 & 0.41 \\
\hline Heart & 1.85 & 1.76 & 1.10 & 1.00 & 0.92 & 2.18 & 1.42 & 1.38 & 0.91 & 0.70 & 0.26 \\
\hline Brain & 1.52 & 1.35 & 0.77 & 0.26 & 0.17 & 0.28 & 0.17 & 0.11 & 0.17 & 0.23 & 0.12 \\
\hline Testis & 1.81 & 1.35 & 1.30 & 1.22 & 0.58 & 0.68 & 0.34 & 0.42 & 0.49 & 0.59 & 0.44 \\
\hline Muscle & 2.15 & 1.36 & 1.07 & 0.40 & 0.13 & 1.01 & 0.80 & 0.78 & 0.46 & 0.48 & 0.11 \\
\hline Plasma & 1.98 & 1.92 & 1.10 & 0.80 & - & 1.62 & 1.12 & 0.71 & 0.67 & 0.64 & 0.23 \\
\hline
\end{tabular}

Each value represents the mean of four animals.

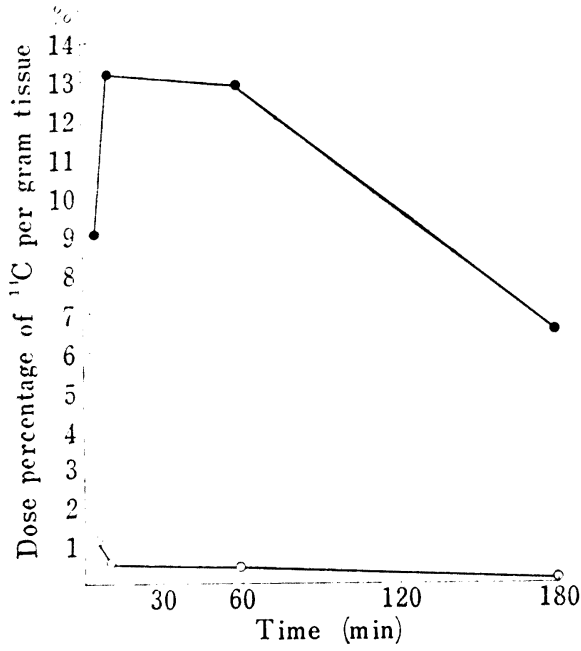

Fig. 11. Time-Course of ${ }^{14} \mathrm{C}-\mathrm{CRD}-401$ and Its Metabolites in the Liver of Mice after $i . v$. Injection of ${ }^{14} \mathrm{C}-\mathrm{CRD}$ 401

- C-: ${ }^{14} \mathrm{C}-\mathrm{CRD}-401$

Each point represents the mean value of four animals.

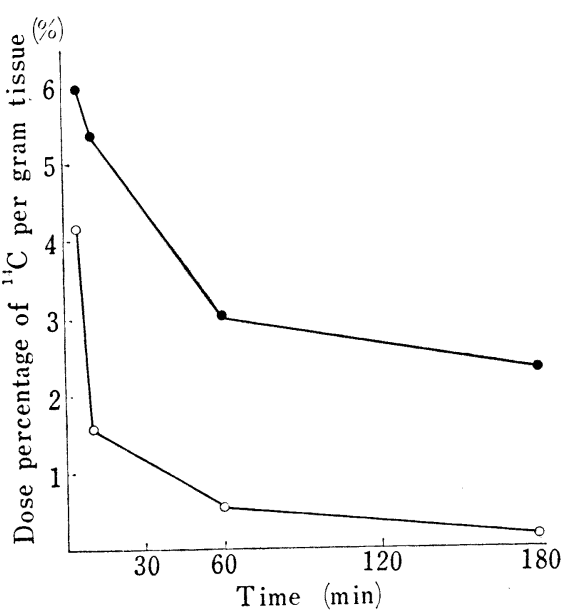

Fig. 12. Time-Course of ${ }^{14} \mathrm{C}-\mathrm{CRD}-401$ and Its Metabolites in the Kidney of Mice after $i . v$. Injection of ${ }^{14} \mathrm{C}-\mathrm{CRD}$ 401

一O- : ${ }^{14} \mathrm{C}-\mathrm{CRD}-401$

Each point represents the mean value of four animals.

The percentages of the unchanged compound were apparently lower after oral administration than after $i . v$. one.

\section{Discussion}

${ }^{14} \mathrm{C}-\mathrm{CRD}-401$ was rapidly and easily absorbed from the digestive tract and the radioactivity in each organ reached its maximum level within $30 \mathrm{~min}$ after p.o. administration.

The marked fall in the levels of radioactivity in the various organs by pyloric ligation suggested that absorption of this compound took place mainly in the intestinal tract. In this connection, it was demonstrated by Sato, et al. ${ }^{2)}$ that intraduodenum administration of CRD-401 produced an considerable increasing of the coronary blood flow. 


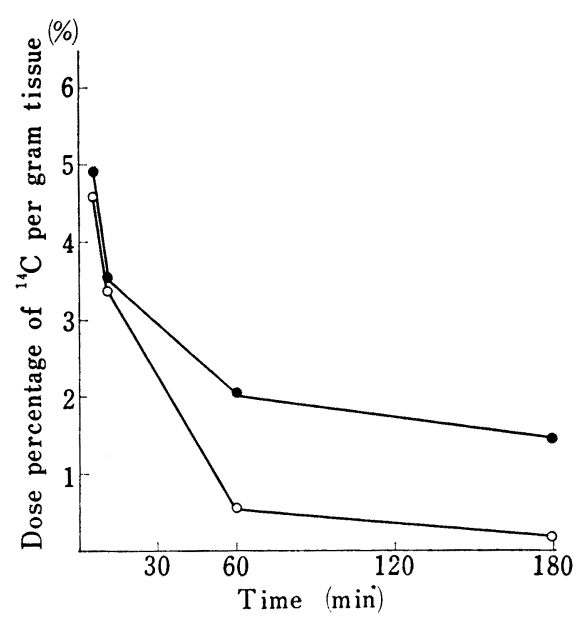

Fig. 13. Time-Course of ${ }^{14} \mathrm{C}-\mathrm{CRD}-401$ and Its Metabolites in the Lung of Mice after $i . v$. Injection of ${ }^{14} \mathrm{C}-\mathrm{CRD}$ 401

-O-: ${ }^{14} \mathrm{C}-\mathrm{CRD}-401 \quad-0-{ }^{14} \mathrm{C}$-metabolites

Each point represents the mean value of four animals.

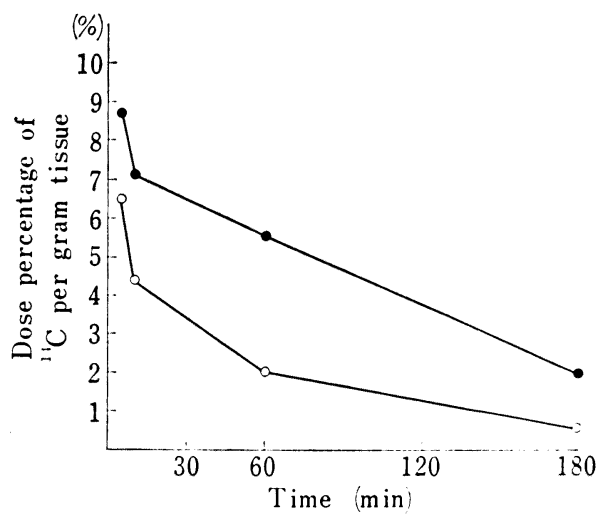

Fig. 14. Time-Course of ${ }^{14} \mathrm{C}-\mathrm{CRD}-401$ and Its Metabolites in the Brain of Mice after $i . v$. Injection of ${ }^{14} \mathrm{C}-\mathrm{CRD}$ 401

-O-: ${ }^{14} \mathrm{C}-\mathrm{CRD}-401 \quad-0$ - ${ }^{14} \mathrm{C}$-metabolites

Each point represents the mean value of four animals.

The autoradiographic pictures obtained with mice immediately after $i . v$. injection were characterized by the rapid disappearance of the radioactivity from the blood flow and the high uptake in the lung, heart muscle, adrenal cortex, kidney, skeletal muscle, blood vessel walls and brain. This distribution pattern was not unique for ${ }^{14} \mathrm{C}-\mathrm{CRD}-401$ but was similar to that of ${ }^{35} \mathrm{~S}$-chlorpromazine, ${ }^{4)}{ }^{14} \mathrm{C}$-imipramine, ${ }^{5)}{ }^{14} \mathrm{C}$-benzodiazepin-group ${ }^{6,7)}$ or ${ }^{14} \mathrm{C}$-meprobamate-group ${ }^{8,9)}$ which acted on the central nervous system.

Pharmacological investigations on CRD-401 have demonstrated that the cardiovascular system was effected by this compound, and the vasodilating action of CRD- 401 was due to the direct action on the blood vessels. ${ }^{2)}{ }^{14} \mathrm{C}-\mathrm{CRD}-401$ was rapidly and greatly taken up in the heart muscle and blood vessels immediately after $i . v$. injection, although it was considerably decreased within the following $5 \mathrm{~min}$. It is recognized that the site of accumulation of a drug does not necessarily correspond to its site of action, and the dose used in this experiments of $2 \mathrm{mg} / \mathrm{kg}(i . v$.) was very large in comparison with the minimal effective dose of $0.02 \mathrm{mg} / \mathrm{kg}$ (i.v.) in the dog. ${ }^{2}$ However, it was likely that such initial high concentration in the heart muscle and blood vessels was somewhat correlated with cardiovascular action of CRD-401 since the significant increasing of coronary blood flow was detected in the dog immediately after $i . v$. injection of the compound. ${ }^{2)}$

A rapid accumulation of radioactivity was also observed in the brain at the first stage of i.v. injection of ${ }^{14} \mathrm{C}-\mathrm{CRD}-401$. The radioactivity, however, diminished greatly within the following $5 \mathrm{~min}$. The distribution pattern of ${ }^{14} \mathrm{C}-\mathrm{CRD}-401$ in the brain was apparently different from that of ${ }^{35} \mathrm{~S}$-chlorpromazine, ${ }^{4)}{ }^{14} \mathrm{C}$-imipramine ${ }^{5)}$ and other compounds ${ }^{6-9)}$ described above which showed a high uptake and long retention of radioactivity in that organ, probably owing to their antipsychotic action.

4) S.E. Sjöstrand, G.B. Cassano and E. Hansson, Arch. Intern. Pharmacodyn., 34, 156 (1965).

5) G.B. Cassano and E. Hansson, Intern. J. Neuropsychiat., 2, 269 (1966).

6) E.Van Der Kleijn, Arch. Intern. Pharmacodyn., 178, 193 (1969).

7) G.F. Placidi and G.B. Cassano, Int. J. Neuropharmacol., 7, 383 (1968).

8) E. Van Der Kleijn, Arch. Intern. Pharmacodyn., 178, 457 (1969).

9) B. Ewaldsson, Arch. Intern. Pharmacodyn., 142, 163 (1963). 
In the autoradiograms after $i . v$. injection of ${ }^{14} \mathrm{C}-\mathrm{CRD}-401$ there was a high accumulation of radioactivity in the glandular, exclusive of non-glandular, part of the stomach. This finding suggested that this accumulation was mediated through an active transportion, probably contribution to the secretion into the lumen. Schanker ${ }^{10)}$ has demonstrated that the passage of drugs from the plasma ( $\mathrm{pH} 7.4)$ to the gastric juice $(\mathrm{pH} 1)$ depends on their $\mathrm{pKa}$ values. The weak basic and lipophilic properties of CRD-401 might explain the excretion of the compound into the lumen of the stomach.

From the autoradiograms of the compound administered $i . v$, the main excretion route seemed to be via the bile. The gall bladder and interloblar bile ducts showed large amounts of radioactivity throughout the observation period. The increasing amounts of radioactive materials in the intestinal contents supported this fact.

${ }^{14} \mathrm{C}-\mathrm{CRD}-401$ and/or its metabolites slightly penetrated the placental barrier. The elimination of radioactive materials from the fetuses seemed to occure through the yolk sac where the radioactivity was detected for long time.

Chromatographic investigations revealed that the metabolism of the compound in mice was very rapid. In fact $1 \mathrm{hr}$ after the $i . v$. injection, the unchanged compound represented only 16 to $27 \%$ of the total radioactivity in the kidney, lung and brain. Metabolism was especially rapid in the liver, where the original compound was only accounted for $11 \%$ of the total radioactivity within $5 \mathrm{~min}$ after the $i . v$. injection. More than $50 \%$ of the total radioactivity in the brain was due to the unchanged compound at $5 \mathrm{~min}$ after, although higher amounts of unchanged compound remained there for longer time than in any other organs examined. Metabolic data of ${ }^{14} \mathrm{C}-\mathrm{CRD}-401$ in rat indicated that only $0.1 \%$ of the radioactivity administered was recovered unchanged from the $24 \mathrm{hr}$ urine or bile. ${ }^{3)}$

The rapid metabolic degradation of $\mathrm{CRD}-401$ and its rapid elimination might explain the low toxicity of the compound.

Acknowledgement We wish to express our grateful thanks to Dr. K. Abe, Director of Biological Research Laboratory, Tanabe Seiyaku Co., Ltd., for his encouragement. The skillful technical assistance of Miss M. Yaitabashi is also gratefully acknowledged.

10) L.S. Schanker, Pharmacol. Rev., 14, 501 (1962). 